\title{
Retrosigmoid Craniectomy for Vestibular Schwannoma with Hearing Preservation
}

\author{
Anthony M. Tolisano ${ }^{1}$ Ankur R. Patel ${ }^{2}$ Samuel L. Barnett ${ }^{2}$ Brandon Isaacson ${ }^{1}$ \\ ${ }^{1}$ Department of Otolaryngology-Head and Neck Surgery, University \\ of Texas Southwestern Medical Center, Dallas, Texas, \\ United States \\ 2 Department of Neurological Surgery, University of Texas \\ Southwestern Medical Center at Dallas, Dallas, Texas, \\ United States \\ Address for correspondence Anthony M. Tolisano, MD, Department \\ of Otolaryngology-Head and Neck Surgery, University of Texas \\ Southwestern Medical Center, 5323 Harry Hines Blvd, Dallas, TX \\ 75390, United States (e-mail: anthony.tolisano@gmail.com). \\ J Neurol Surg B 2019;80(suppl S3):S274-S275.
}

Conflict of Interest None.

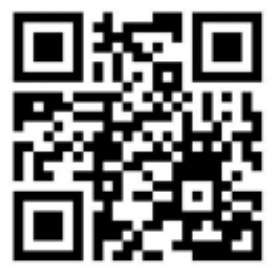

received

May 30, 2018

accepted

August 19, 2018

published online

October 15, 2018
Objectives To describe a retrosigmoid craniectomy, hearing-preservation approach for resection of vestibular schwannoma.

Design/Setting/Participants A video of a single patient undergoing the above approach at a tertiary care skull base surgery program.

Results This video demonstrates a retrosigmoid craniectomy approach for resection of an enlarging intracanalicular vestibular schwannoma in a patient with normal hearing. The video highlights the pertinent surgical anatomy and outlines in a stepby-step fashion the surgical steps. The patient obtained a gross total resection with preservation of hearing.

Conclusion A retrosigmoid craniectomy approach for vestibular schwannoma offers a potentially hearing preservation approach for selected tumors.

The link to the video can be found at: https://youtu.be/VM663XztRZw. www.thieme.com/skullbasevideos

www.thieme.com/jnlsbvideos

DOI https://doi.org/

10.1055/s-0038-1675148.

ISSN 2193-6331. (c) 2019 Georg Thieme Verlag KG
Stuttgart · New York

License terms

(c) $\odot \ominus$ 


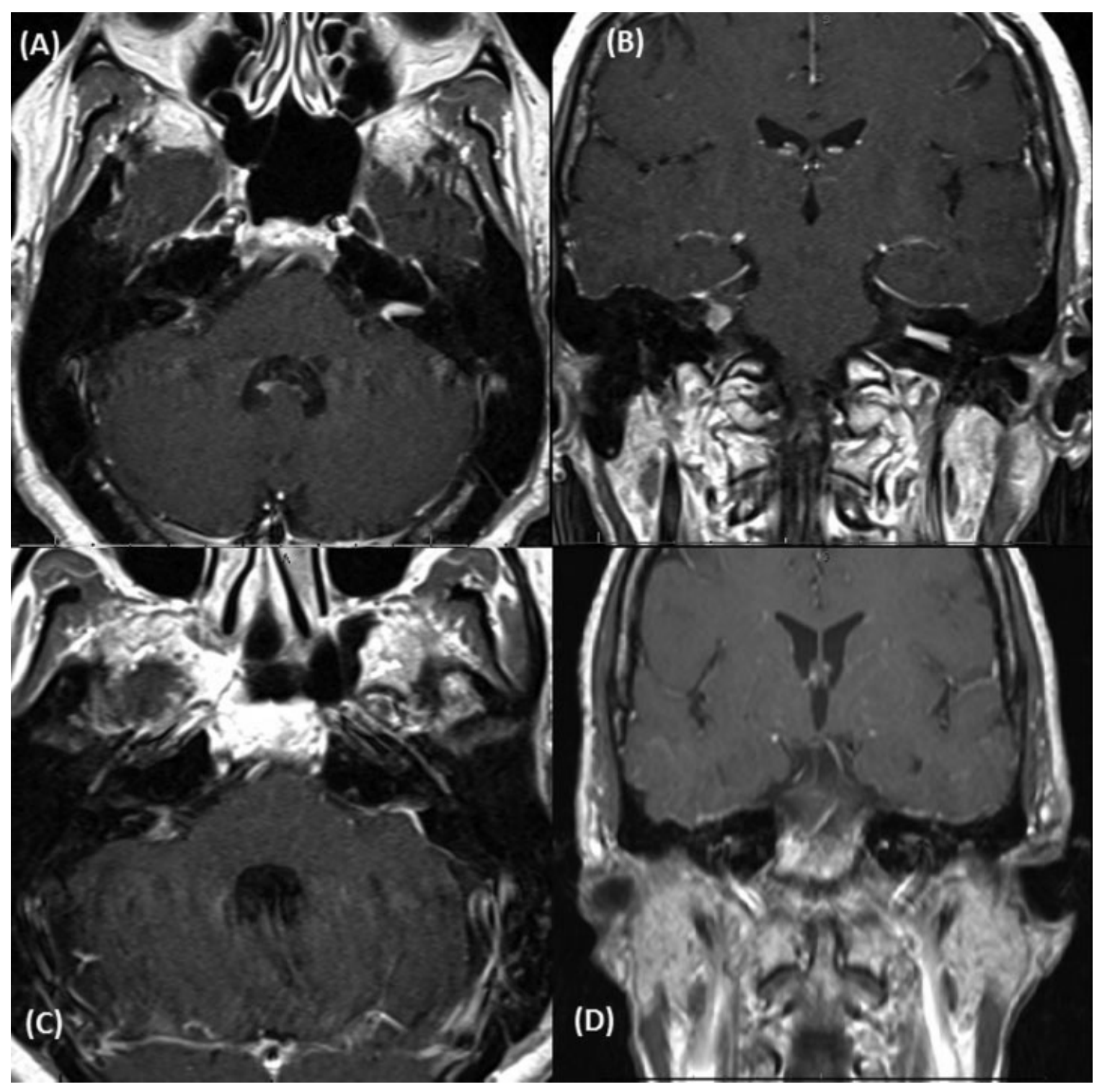

Fig. 1 T1-weighted magnetic resonance images with gadolinium demonstrating (A) preoperative axial, (B) preoperative coronal, (C) postoperative axial, and (D) postoperative coronal images of a left intracanalicular vestibular schwannoma. 